\title{
PERBANDINGAN METODE SAW DAN METODE SMART DALAM PEMILIHAN KULINER KHAS KALIMANTAN SELATAN TERBAIK
}

\author{
Agus Alim Muin ${ }^{1}$ \\ ${ }^{1}$ Fakultas Teknologi Informasi,Universitas Islam Kalimantan Muhammad Arsyad Albanjari Banjarmasin \\ Email: Alim.blues@gmail.com
}

\begin{abstract}
Abstrak
Penelitian ini mengkaji tentang berbagai Kuliner tradisional masyarakat Khas Kalimantan Selatan. Makanan sendiri bukan sekedar produk organisme dengan kualitas biokimia yang dikonsumsi manusia, tetapi makanan merupakan bagian dari upaya mempertahankan hidup yang juga ditentukan oleh kebudayaan masing-masing daerah. Keberadaan makanan atau Kuliner Khas Kalimantan Selatan sekarang sudah mulai tidak dikenal oleh generasi muda seiring dengan masuknya berbagai produk makanan impor. Generasi sekarang sudah tidak lagi memahami makna dan kearifan lokal dari makanan daerah. Hasil penelitian ini menemukan bahwa ada beberapa makanan atau kuliner Khas Kalimantan Selatan yang masih berkembang, berdasarkan hasil wawancara dan angket adalah 4 kriteria: Harga (C1), Rasa (C2), Kemudahan Akses Ke Lokasi (C3), Daya Tahan Makanan (C4) dan produk makan yang digunakan adalah 4 Alternatif: Soto Banjar (V1), Nasi Itik Gambut (V2), Ketupat Kandangan (V3), Lontong Orari (V4). Dari hasil perhitungan dengan menggunakan Metode SAW didapatkan kuliner Soto Banjar menempati urutan pertama dengan nilai sebesar 0,889. Lontong Orari menempati menempati urutan kedua dengan nilai sebesar 0.847, Ketupat Kandangan urutan ketiga dengan nilai sebesar 0,816, dan Nasi Itik Gambut sebagai urutan keempat dengan nilai sebesar 0,797 dan Hasil perhitungan dengan menggunakan Metode SMART di dapatkan kuliner Soto Banjar menempati urutan pertama dengan nilai sebesar 0.7, ketupat kandangan menempati urutan kedua dengan nilai sebesar 0.51, Lontong Orari menempati urutan ketiga dengan nilai sebesar 0,37, dan Nasi Itik Gambut sebagai urutan keempat dengan nilai sebesar 0,3
\end{abstract}

Keyword: Kuliner Khas Kalimantan Selatan, Sistem Pendukung Keputusan, Simple Additive Weighting (SAW),Simple Multi Attribute Rating Technique (SMART)

\section{PENDAHULUAN}

Kuliner Khas Kalimantan Selatan adalah makanan yang biasa di konsumsi bersama keluarga. Karakter masakan di suatu daerah biasanya mencerminkan karakter masyarakatnya. Misalkan daerah pegunungan menghasilkan masakan dari sayur mayur karena iklim pegunungan yang dingin, umumnya masakannya serba panas atau pedas, untuk menghangatkan badan. Penduduk di daerah pesisir sering kontak dengan orang asing atau daerah lain sehingga melahirkan banyak masakan campuran yang ikut memperkaya produk makanan khas daerah tersebut.

Berdasarkan permasalah tersebut, peneliti menggunakan cabang ilmu SPK dalam menyelesaikan kasus tersebut. Mengingat SPK adalah cabang ilmu yang dapat menyelesaikan permasalahan perangkingan.

Beberapa metode SPK yang digunakan dalam proses pengambilan keputusan diantarannya metode Weighted Product, Analytic Hierarchy Process,SAW,SMART,PROMETHEE,Topsis,

VIKOR dll. Peneliti menggunakan Metode Simple Additive Weighting (SAW) dan Simple Multi Attribute Rating Technique (SMART) karena dapat mencari penjumlahan terbobot dari rating kinerja pada setiap alternatif di semua atribut. Metode ini sendiri sebenarnya masih termasuk dalam metode MADM atau Multiple Attribute Decision Making. Ini merupakan salah satu metode MADM klasik untuk menentukan penjumlahan terbobot pada setiap atribut.

Metode SAW dan SMART sangat banyak memiliki kegunaan dalam implementasi di kehidupan masyarakat seperti melakukan penilaian suatu karyawan di perusahaan, pemilihan siswa 
berprestasi, rekomendasi pencari kerja terbaik, dsb.

Penelitian tentang makanan ini menjadi penting karena cukup banyak generasi sekarang yang sudah tidak lagi mengenal makanan khas daerah di tengah gemburan banyaknya produk makanan impor. Penelitian ini bukan sekedar upaya diskriptif tentang berbagai folklore bukan lisan khususnya makanan atau kuliner tradisional yang ada di kalangan masyarakat Banjar tetapi lebih jauh adalah upaya mencoba memahami apa yang menjadi harapan dan angan-angan orang Banjar tentang kebudayaannya serta sekaligus untuk menambah pengetahuan tentang keaneka ragaman budaya yang ada di Nusantara.

Tujuan khusus penelitian ini adalah untuk mengidentifikasi berbagai makanan daerah masyarakat Khas Kalimantan Selatan yang biasa disantap dan disajikan serta menggali fungsi social budaya dari makanan tersebut, baik kaitannya dengan bahan makanan, proses pengolahan maupun penyajiannya

\section{METODE PENELITIAN}

Penelitian ini dilakukan di Kota Banjarmasin, Kalimantan Selatan. Metode yang digunakan adalah Simple Additive Weighting (SAW) dan metode SMART (Simple Multi Attribute Rating Technique) Data diambil dengan cara melakukan wawancara dan membagikan angket secara acak kepada 50 orang yang pernah mencicipi kuliner yang bertusia 25-40 tahun. Kriteria yang digunakan adalah 4 kriteria: Harga (C1), Rasa (C2), Kemudahan Akses Ke Lokasi (C3), Daya Tahan Makanan (C4) dan produk makan yang digunakan adalah 4 Alternatif: Soto Banjar (V1), Nasi Itik Gambut (V2), Ketupat Kandangan (V3), Lontong Orari (V4).

\section{A. Sistem Pendukung Keputusan}

Merupakan bagian dari sistem informasi berbasis komputer yang mengolah data menjadi informasi untuk mengambil keputusan dari masalah semi terstruktur yang spesifik

\section{B. Simple Additive Weighting (SAW)}

Simple Additive Weighting ( $S A W$ ) atau dikenal dengan istilah metode penjumlahan terbobot. Konsep dasar pada metode SAW adalah mencari penjumlahan terbobot dari rating kinerja pada setiap alternatif di semua atribut. Metode SAW Jurnal Ilmiah “Technologia” membutuhkan proses normalisasi matriks keputusan (X) ke suatu skala yang dapat diperbandingkan dengan semua rating alternatif yang ada.

Formula untuk melakukan normalisasi tersebut adalah:

$r_{i j}=\left\{\begin{array}{l}\frac{X i j}{M a x X i j} \text { jika jialah atribut keuntungan (bebefit) } \\ \frac{M i n X i j}{X i j} \quad \text { jika j ialah atribut biaya (cost) }\end{array}\right.$

Keterangan :

rij = nilai rating kinerja ternormalisasi

xij = nilai atribut yang dimiliki dari setiap kriteria

Max xij = nilai terbesar dari setiap kriteria ${ }_{i}$

Min xij $=$ nilai terkecil dari setiap kriteria ${ }_{i}$

benefit $=$ jika nilai terbesar adalah terbaik

cost $=$ jika nilai terkecil adalah terbaik dimana rij adalah rating kinerja ternormalisasi dari alternatif Ai pada atribut $\mathrm{Cj} ; \mathrm{i}=1,2, \ldots, \mathrm{m}$ dan $\mathrm{j}=1,2, \ldots, \mathrm{n}$.

Nilai preferensi untuk setiap alternatif (Vi) diberikan sebagai:

$$
\mathrm{Vi}=\sum_{j=1}^{n} \mathrm{Wj} \mathrm{r} i j
$$

Keterangan :

$\mathrm{Vi}=$ rangking untuk setiap alternatif

$\mathrm{wj}=$ nilai bobot dari setiap kriteria

rij = nilai rating kinerja ternormalisasi

Nilai Vi yang lebih besar mengindikasikan bahwa alternatif Ai lebih terpilih.

\section{SMART (Simple Multi Attribute Rating Technique).}

SMART (Simple Multi Attribute Rating Technique) merupakan metode pengambilan keputusan yang multi atribut yang dikembangkan oleh Edward pada tahun 1977. Teknik pembuatan keputusan multiatribut ini digunakan untuk mendukung pembuat keputusan dalam memilih antara beberapa alternatif. Setiap pembuat keputusan harus memilih sebuah alternatif yang sesuai dengan tujuan yang telah dirumuskan. Setiap alternatif terdiri dari sekumpulan atribut dan setiap atribut mempunyai nilai-nilai. Nilai ini dirata-rata dengan skala tertentu.

Setiap atribut mempunyai bobot yang menggambarkan seberapa penting dibandingkan 
dengan atribut lain. Pembobotan dan pemberian peringkat ini digunakan untuk menilai setiap alternatif agar diperoleh alternatif terbaik. Pembobotan pada SMART (Simple Multi Attribute Rating Technique) menggunakan skala 0-100 berdasarkan prioritas yang telah diinputkan kemudian dilakukan normalisasi.

berikut adalah langkah Perhitungan Manual

Metode Smart :

normalisasi bobot

$$
\frac{W j}{\sum W j}
$$

Hitung nilai utility untuk setiap kriteria masing masing:

$$
\begin{aligned}
& \mathrm{Ui}(\mathrm{ai})=\frac{(\mathrm{cmax}-\mathrm{cout})}{(\mathrm{cmax}-\mathrm{cmin})} \\
& \mathrm{Ui}(\mathrm{ai})=\frac{(\text { ccost })}{(\text { cmat }-\mathrm{cmin})} \\
& (\text { benefit })
\end{aligned}
$$

Keterangan :

ui(ai) : nilai utility kriteria ke-1 untuk kriteria ke-i

Cmax : nilai kriteria

maksimal Cmin : nilai

kriteria minimal Cout i :

nilai kriteria ke-i

$\mathrm{U}(\mathrm{ai})=\sum W j * U i(a i) m J=1$

\section{HASIL DAN PEMBAHASAN}

\section{A. Penentuan Alternatif}

Proses penentuan alternatif dilakukan dengan melakukan observasi secara langsung dan wawancara kepada kepada 50 orang yang mencicipi kuliner yang bertusia 25-40 tahun di Kota Banjarmasin, Kalimantan Selatan. Dari hasil tersebut diperoleh Kuliner Khas Kalimantan Selatan seperti yang ditunjukan pada table berikut:

Tabel 1

\section{$\underline{\text { Alternatif }}$}

\begin{tabular}{lc}
\multicolumn{1}{c}{ Alternatif } & Keterangan \\
\hline Soto Banjar & V1 \\
Nasi Itik Gambut & V2 \\
Ketupat Kandangan & V3 \\
\hline
\end{tabular}

Jurnal Ilmiah “Technologia”
Lontong Orari

V4

Pada Tabel 1. menunjukkan nama alternatif atau makanan yang dipakai dalam pemilihan Kuliner Khas Kalimantan Selatan

\section{B. Penentuan Kriteria \\ Adapun kriteria yang digunakan pada pemilihan makanan yang terbaik menurut pelanggan atau penguji seperti yang ditunjukkan pada tabel berikut:}

\begin{tabular}{|c|c|c|}
\hline Kriteria & Keterangan Kriteria & Ket \\
\hline Kriteria 1 & Harga & $\mathrm{C} 1$ \\
\hline Kriteria 2 & Rasa & $\mathrm{C} 2$ \\
\hline Kriteria 3 & $\begin{array}{l}\text { Kemudahan Akses Ke } \\
\text { Lokasi }\end{array}$ & $\mathrm{C} 3$ \\
\hline Kriteria 4 & Daya Tahan Makanan & $\mathrm{C} 4$ \\
\hline
\end{tabular}

Tabel 2.

$\frac{\text { Kriteria Pemilihan Kuliner Khas Kalimantan }}{\underline{\text { Selatan }}}$

Pada Tabel 2. menunjukkan bahwa Kriteriakriteria yang diambil dalam pemilihan Kuliner Khas Kalimantan Selatan

\section{Konfigurasi nilai kriteria}

Peneliti memberikan nilai kriteria pada semua alternatif. Pemberian nilai kriteria sebagai berikut : 


\begin{tabular}{|c|c|c|}
\hline Kriteria & Parameter & $\begin{array}{c}\text { Nilai } \\
\text { bobot } \\
\text { kriteria }\end{array}$ \\
\hline \multirow{6}{*}{ Harga } & Mahal & 1 \\
\hline & Sedang & 2 \\
\hline & Cukup & 3 \\
\hline & Murah & \\
\hline & Murah & 4 \\
\hline & $\begin{array}{l}\text { Sangat } \\
\text { murah }\end{array}$ & 5 \\
\hline \multirow{5}{*}{ Rasa } & Biasa & 1 \\
\hline & Sedang & 2 \\
\hline & Cukup enak & 3 \\
\hline & Enak & 4 \\
\hline & Sangat enak & 5 \\
\hline \multirow{5}{*}{$\begin{array}{c}\text { Kemudahan akses ke } \\
\text { lokasi }\end{array}$} & Sulit & 1 \\
\hline & Sedang & 2 \\
\hline & $\begin{array}{l}\text { Cukup } \\
\text { mudah }\end{array}$ & 3 \\
\hline & Mudah & 4 \\
\hline & $\begin{array}{l}\text { Sangat } \\
\text { mudah }\end{array}$ & 5 \\
\hline \multirow{5}{*}{ Daya tahan makanan } & Tidak awet & 1 \\
\hline & Sedang & 2 \\
\hline & Cukup awet & 3 \\
\hline & Awet & 4 \\
\hline & Sangat awet & 5 \\
\hline
\end{tabular}

D. Penerapan metode Simple Additive Weighting (SAW)

Berikut data penelitian yang digunakan dimana sebelumnya data telah direkapitulasi menggunakan bantuan software microsoft excel. Hasil lengkap hitung rata-rata Kriteria-kriteria yang ditunjukan pada berikut:

Tabel 3

$\underline{\text { Rating Kecocokan Setiap Alternatif Pada }}$

\section{$\underline{\text { Setiap Kriteria }}$}

\begin{tabular}{llcccc} 
& & \multicolumn{4}{c}{ Kriteria } \\
No & Alterenatif & \multicolumn{4}{c}{} \\
& & C1 & C2 & C3 & C4 \\
\hline 1 & Soto Banjar & 3.8 & 4 & 4.4 & 3.6 \\
2 & Nasi Itik & 2.4 & 3 & 2.6 & 2.8 \\
& gambut & & & & \\
3 & Ketupat & 3.4 & 3.6 & 3 & 3.6 \\
\hline
\end{tabular}

Tabel 4. Nilai Bobot

Kriteria BOBOT

\begin{tabular}{lc}
\hline Harga $(\mathrm{C} 1)$ & 0.3 \\
Rasa $(\mathrm{C} 2)$ & 0.3 \\
$\begin{array}{l}\text { Kemudahan Akses Ke Lokasi } \\
\text { (C3) }\end{array}$ & 0.2 \\
Daya Tahan Makanan (C4) & 0.2 \\
\hline
\end{tabular}

Data penelitian pada tabel 3, akan dilakukan perhitungan Normalisasi dengan formula seperti berikut:

1. Nilai Kriteria Harga (C1)

$\mathrm{r} 11=\frac{\min \{3.8 ; 2.4 ; 3.4 ; 2.6 ;\}}{3.8}=\frac{2,4}{3.8}=0,63$

$\mathrm{r} 21=\frac{\min \{3.8 ; 2.4 ; 3.4 ; 2.6 ;\}}{2,4}=\frac{2.4}{2,4}=1$

$\mathrm{r} 31=\frac{\min \{3.8 ; 2.4 ; 3.4 ; 2.6 ;\}}{3.4}=\frac{2.4}{3.4}=0.70$

$\mathrm{r} 41=\frac{\min \{3.8 ; 2.4 ; 3.4 ; 2.6 ;\}}{2,6}=\frac{2.4}{2.6}=0.92$

2. Nilai Kriteria Rasa (C2)

$\mathrm{r} 12=\frac{4}{\max \{4 ; 3 ; 3.6 ; 3.4 ;\}}=\frac{4}{4}=1$

$\mathrm{r} 22=\frac{3}{\max \{4 ; 3 ; 3.6 ; 3.4 ;\}}=\frac{3}{4}=0.75$

Jurnal Ilmiah "Technologia” 
$\mathrm{r} 32=\frac{3.6}{\max \{4 ; 3 ; 3.6 ; 3.4 ;\}}=\frac{3.6}{4}=0.9$

$\mathrm{r} 42=\frac{3.4}{\max \{4 ; 3 ; 3.6 ; 3.4 ;\}}=\frac{3.4}{4}=0.85$

3. Nilai Kriteria Kemudahan Akses Kelokasi

$\mathrm{r} 13=\frac{4.4}{\max \{4.4 ; 2.6 ; 3 ; 3.6 ;\}}=\frac{4.4}{4.4}=1$

$\mathrm{r} 23=\frac{2.6}{\max \{4.4 ; 2.6 ; 3 ; 3.6 ;\}}=\frac{2.6}{4.4}=0.59$

$\mathrm{r} 33=\frac{3}{\max \{4.4 ; 2.6 ; 3 ; 3.6 ;\}}=\frac{3}{4.4}=0.68$

$\mathrm{r} 43=\frac{3.6}{\max \{4.4 ; 2.6 ; 3 ; 3.6 ;\}}=\frac{3.6}{4.4}=0.81$

4. Nilai Kriteria Daya Tahan Makanan

$\mathrm{r} 14=\frac{3.6}{\max \{3.6 ; 2.8 ; 3.6 ; 2.8 ;\}}=\frac{3.6}{3.6}=1$

$\mathrm{r} 24=\frac{2.8}{\max \{3.6 ; 2.8 ; 3.6 ; 2.8 ;\}}=\frac{2.8}{3.6}=0.77$

$\mathrm{r} 34=\frac{3.6}{\max \{3.6 ; 2.8 ; 3.6 ; 2.8 ;\}}=\frac{2.8}{3.6}=1$

$\mathrm{r} 44=\frac{2.8}{\max \{3.6 ; 2.8 ; 3.6 ; 2.8 ;\}}=\frac{2.8}{3.6}=0.77$

Berikut hasil lengkap Hasil Normalisasi seperti yang ditunjukan pada berikut:

Hasil Normalisasi:

$R=\left[\begin{array}{cccc}0.63 & 1 & 1 & 1 \\ 1 & 0.75 & 0.59 & 0.77 \\ 0.7 & 0.9 & 0.68 & 1 \\ 0.92 & 0.85 & 0.81 & 0.77\end{array}\right]$

Hasil akhir yang di ranking dari perhitungan yang banyak peminat Kuliner Khas Kalimantan Selatan dalam kriteria Harga (C1), Rasa (C2), Kemudahan Akses ke Loakasi (C3), Daya Tahan Makanan (C4) yang ditunjukan pada berikut:

Bobot yang diberikan : [ [ $\left.\begin{array}{llll}0.3 & 0.3 & 0.2 & 0.2\end{array}\right]$
Tabel 5.

Hasil Lengkap Perhitungan

\section{Alternatif Nilai Preferensi}

Hasil

\begin{tabular}{lll} 
Soto & $(0.3)(0.63)+(0.3)(1)+$ & 0,889 \\
Banjar & $(0.2)(1)+(0.2)(1)=$ & \\
Nasi Itik & $(0.3)(1)+(0.3)(0.75)+$ & 0,797 \\
Gambut & $(0.2)(0.59)+(0.2)(0.77)=$ & \\
Ketupat & $(0.3)(0.7)+(0.3)(0.9)+$ & 0,816 \\
Kandangan & $(0.2)(0.68)+(0.2)(1)=$ & \\
Lontong & $(0.3)(0.92)+(0.3)(0.85)+$ & 0,847 \\
Orari & $(0.2)(0.81)+(0.2)(0.77)=$ & \\
\hline
\end{tabular}

Pada table 5, hasil perhitungan akhir sudah dapat dilakukan dengan melihat nilai tertinggi berdasarkan hitungan Simple Additive Weighting (SAW) yang banyak peminat dari Harga, Rasa, Tempat Ke Lokasi, dan Daya Tahan Makanan adalah ke 1. Soto (V1), 2. Lontong Orari (V4), 3. Ketupat Kandangan (V3), dan 4. Nasi Itik Gambut (V2)

\section{E. Penerepan Metode SMART}

Dari data penelitian pada tabel 3, akan dilakukan perhitungan Nilai Utility seperti berikut:

Tabel 6.

Perrhitungan nilai Utility

\begin{tabular}{|c|c|c|c|c|}
\hline \multirow{2}{*}{$\begin{array}{c}\text { Alter } \\
\text { natif }\end{array}$} & \multicolumn{4}{|c|}{ Kriteria } \\
\hline & C1 & $\mathrm{C} 2$ & C3 & $\mathrm{C} 4$ \\
\hline \multirow[t]{2}{*}{ V1 } & $3.8-3.8=0$ & $4-3=1$ & $4.4-2.6=1$ & $3.6-2.8$ \\
\hline & $\overline{3.8-2.4}=0$ & $\overline{4-3}=1$ & $\overline{4.4-2.6}=1$ & $\begin{array}{l}3.6-2.8 \\
=1\end{array}$ \\
\hline \multirow[t]{2}{*}{ V2 } & $3.8-2.4$ & & $2.6-2.6$ & $2.8-2.8$ \\
\hline & $3.8-2.4=1$ & $\frac{3-3}{4-3}=0$ & $\frac{.6}{4.4-2.6}=0$ & $\begin{array}{l}3.6-2.8 \\
=0\end{array}$ \\
\hline \multirow{2}{*}{ V3 } & $3.8-3.4$ & $\begin{array}{l}4-3 \\
3.6-3\end{array}$ & $3-2.6$ & $3.6-2.8$ \\
\hline & $\begin{array}{l}\overline{3.8-2.4} \\
=0.28 \\
3.8-2\end{array}$ & $\begin{array}{l}\overline{4-3} \\
=0.6\end{array}$ & $\begin{array}{l}\overline{4.4-2.6} \\
=0.22 \\
20\end{array}$ & $\begin{array}{l}3.6-2.8 \\
=1\end{array}$ \\
\hline \multirow[t]{2}{*}{ V4 } & $3.8-2.6$ & $3.4-3$ & $2.6-2.6$ & $2.8-2.8$ \\
\hline & $\begin{array}{l}3.8-2.4 \\
=0.85\end{array}$ & $\begin{array}{l}4-3 \\
=0.4\end{array}$ & $\begin{array}{l}4.4-2.6 \\
=0.22\end{array}$ & $\begin{array}{l}3.6-2.8 \\
=0\end{array}$ \\
\hline
\end{tabular}

Jurnal Ilmiah “Technologia” 
Hasil perhitungan nilai utility tersebut dirangkum dalam tabel sebagai berikut:

Tabel 7. Hasil Perhitungan Nilai Utility

\begin{tabular}{lcccc} 
Alternatif & \multicolumn{4}{c}{ Kriteria } \\
& C1 & C2 & C3 & C4 \\
\hline V1 & 0 & 1 & 1 & 1 \\
V2 & 1 & 0 & 0 & 0 \\
V3 & 0.28 & 0.6 & 0.22 & 1 \\
V4 & 0.85 & 0.4 & 0.22 & 0 \\
\hline
\end{tabular}

Kemudian menghitung nilai keseluruhan untuk mendapatkan ranking. Berikut seperti ini :

Tabel 8.

Perhitungan Keseleruhan Nilai Utility

\begin{tabular}{ll}
$\begin{array}{c}\text { Altern } \\
\text { atif }\end{array}$ & \multicolumn{2}{c}{ C1 } & \multicolumn{1}{c}{ Kriteria } \\
& \\
\hline V1 & \\
& $(0 * 0.3)+(1 * 0.3)+(1 * 0.2)+(1 * 0.2)=0.7$ \\
V2 & $(1 * 0.3)+(0 * 0.3)+(0 * 0.2)+(0 * 0.2)=0.3$ \\
V3 & $(0.28 * 0.3)+(0.6 * 0.3)+(0.22 * 0.2)+(1 *$ \\
& $0.2)=0.51$ \\
V4 & $(0.85 * 0.3)+(0.4 * 0.3)+(0.22 * 0.2)+(0 *$ \\
& $0.2)=0.37$ \\
\hline
\end{tabular}

Hasil akhir yang diranking dari perhitungan yang makanan terbaik Kuliner Khas Kalimantan Selatan dalam kriteria Harga (C1), Rasa (C2), Kemudahan Akses ke Loakasi (C3), Daya Tahan Makanan (C4) yang ditunjukan pada table berikut:

Tabel 9. Hasil Perangkingan

\begin{tabular}{llll} 
Rangking & Kode & Alternatif & $\begin{array}{l}\text { Total } \\
\text { Nilai }\end{array}$ \\
\hline 1 & A1 & Soto Banjar & 0.7 \\
2 & & Ketupat & 0.51 \\
& A3 & Kandangan & 0.37 \\
4 & A4 & Lontong Orari & Nasi Itik Gambut \\
4 & A2 & 0.3 \\
\hline
\end{tabular}

Hasil Perbandingan metode SAW dan metode SMART adalah sebagai berikut :

Tabel 10. Hasil Perbandingan

\begin{tabular}{clrr} 
No & \multicolumn{1}{c}{ Alternatif } & SAW & SMART \\
\hline 1 & Soto Banjar & 0.889 & 0.7 \\
2 & Nasi Itik gambut & 0.797 & 0.3 \\
3 & Ketupat Kandangan & 0.816 & 0.51 \\
4 & Lontong Orari & 0.847 & 0.37 \\
\hline
\end{tabular}

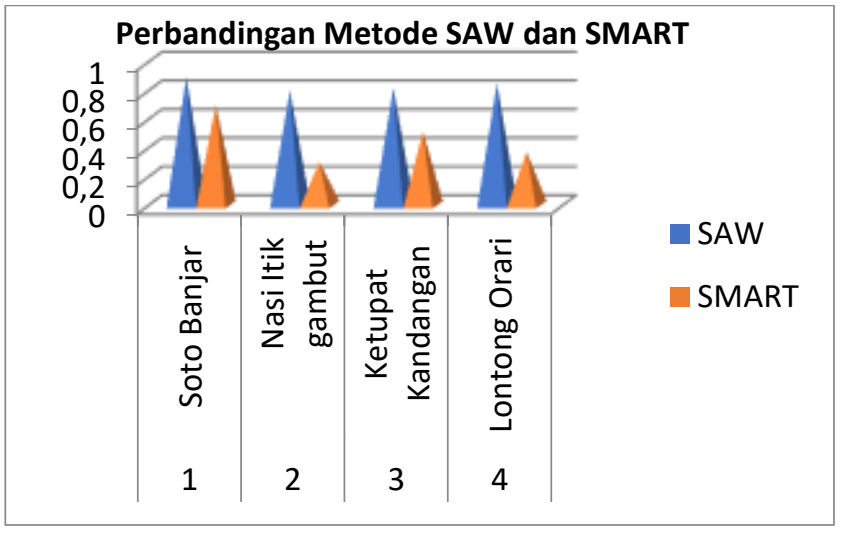

\section{KESIMPULAN}

Berdasarkan hasil penelitian yang dilakukan pada peminat Kuliner Khas Kalimantan Selatan bahwa metode Simple Additive Weighting (SAW) dan metode SMART (Simple Multi Attribute Rating Technique) dapat di terapkan. hasil perhitungan dengan menggunakan Metode SAW didapatkan kuliner Soto Banjar menempati urutan pertama dengan nilai sebesar 0.889, Lontong Orari menempati urutan kedua dengan nilai sebesar 0.847, Ketupat Kandangan menempati urutan ketiga dengan nilai sebesar 0,816, dan Nasi Itik Gambut sebagai urutan keempat dengan nilai sebesar 0,797 dan Hasil perhitungan dengan menggunakan Metode SMART di dapatkan kuliner Soto Banjar menempati urutan pertama dengan nilai sebesar 0.7, ketupat kandangan menempati urutan kedua dengan nilai sebesar 0.51, Lontong Orari menempati urutan ketiga dengan nilai sebesar 0,37, dan Nasi Itik Gambut sebagai urutan keempat dengan nilai sebesar 0,3 sebagai urutan dari yang banyak peminatnya. 


\section{REFERENSI}

[1] Sakti Z.2017. Pengertian Makanan Khas Daerah dan Karakteristiknya. https://www.awalilmu.com/2017/10/penger tian-makanan-khas-daerah-dan-

karakteristiknya.html

Diakses Tanggal 31 bulan juli 2020

[2] Muin, A.A. and Amin, M., 2019. Pemilihan Facial Wash Untuk Kulit Wajah Berminyak Dengan Metode Promethee II. Computer Engineering, Science and System Journal, 4(2), pp.222-229.

[3] Alfisyah, A., 2020. TRADISI MAKAN URANG BANJAR (Kajian Folklor atas Pola Makan Masyarakat Lahan Basah). PADARINGAN (Jurnal Pendidikan Sosiologi Antropologi), 1(3), pp.97-109

[4] Nofriansyah D.2017.Modul Sistem pendukung keputusan https://maam13.files.wordpress.com/2017/ 09/spk-dicky-nofriansyah.pdf

Di akses tanggal 28 juli 2020.

[5] Fishburn, P.C., 1984. Multiattribute nonlinear utility theory. Management Science, 30(11), pp.1301-1310.

[6] MacCrimmon, K.R., 1968. Decisionmaking among multiple-attribute alternatives: a survey and consolidated approach. Rand Corp Santa Monica Ca.

[7] Putra, A.S., Aryanti, D.R. and Hartati, I., 2018, November. Metode SAW (Simple Additive Weighting) sebagai Sistem Pendukung Keputusan Guru Berprestasi (Studi Kasus: SMK Global Surya). In Prosiding Seminar Nasional Darmajaya (Vol. 1, No. 1, pp. 85-97).

[8] Sundari, S.S. and Taufik, Y.F., 2014. Sistem Pendukung Keputusan Penerimaan Pegawai Baru Dengan Menggunakan Metode Simple Additive Weighting (SAW). Sisfotenika, 4(2), pp.140-151.
[9] Ismanto, E. and Effendi, N., 2017. Sistem Pendukung Keputusan Penerimaan Karyawan Dengan Metode Simple Additive Weighting (SAW). SATIN-Sains dan Teknologi Informasi, 3(1), pp.1-9.

[10] Djamain, Y., 2015. Sistem pendukung keputusan penerimaan pegawai baru pt. pln (persero) kantor pusat dengan menggunakan metode simple additive weighting (saw). Jurnal Teknik Informatika, 8(1).

[11] Turban, E. and Aronson, J.E., 2001. Decision Support Systems and Intelligent Systems, 6th edPrentice Hall. Upper Saddle River, NJ.

[12] Edwards, W. and Barron, F.H., 1994. SMARTS and SMARTER: Improved simple methods for multiattribute utility measurement. Organizational behavior and human decision processes, 60(3), pp.306325.

[13] Pangaribuan, A.G.R., Mustika, W.P. and Wanto, A., 2019. Pemilihan Jenis Sapi bagi Peternak Sapi Potong dengan Metode SMART. Algoritm. J. Ilmu Komput. dan Inform, 3(1), pp.30-37.

[14] Rasyid, M. and Si, M.B.S., 2017. Analisa Perbandingan Metode Simple Additive Weighting (SAW) DAN Metode Simple Multi Atribute Rating Technique (SMART) Dalam Pemberian Beasiswa (Studi Kasus Pemerintah Kota Batam).

[15] Muslihudin, M., 2018. Perbandingan Metode Simple Additive Weighting dan Metode Weight Product dalam Penentuan Kelayakan Bengkel Teknik Sepeda Motor Untuk Uji Kompetensi Keahlian Siswa SMK.

[16] Azhari, A.A., Nyura, Y. and Najib, A., 2018, April. Perbandingan Metode Saw dan Topsis Pada Penerimaan Siswa Praktek Kerja Lapangan. In Prosiding SAKTI (Seminar Ilmu Komputer dan Teknologi Informasi) (Vol. 3, No. 1, pp. 71-77). 